\title{
Amelioration on oxidative stress, testosterone, and cortisol levels after administration of Vitamins $C$ and $E$ in albino rats with chronic variable stress
}

\author{
Nanik Hidayatik ${ }^{1}$, Agus Purnomo ${ }^{2}$, Faisal Fikri1 ${ }^{(i)}$ and Muhammad Thohawi Elziyad Purnama ${ }^{3}$ (i)
}

\begin{abstract}
1. Department of Veterinary Clinical Pathology and Physiology, Faculty of Veterinary Medicine, Universitas Airlangga, Surabaya, Indonesia; 2. Department of Veterinary Surgery and Radiology, Faculty of Veterinary Medicine, Universitas Gadjah Mada, Yogyakarta, Indonesia; 3. Department of Veterinary Anatomy, Faculty of Veterinary Medicine, Universitas Airlangga, Surabaya, Indonesia.

Corresponding author: Muhammad Thohawi Elziyad Purnama, e-mail: thohawi@fkh.unair.ac.id Co-authors: NH: nanik.h@fkh.unair.ac.id, AP: agus.fkh@ugm.ac.id, FF: faisalfikri@fkh.unair.ac.id Received: 23-07-2020, Accepted: 01-12-2020, Published online: 18-01-2021
\end{abstract}

doi: www.doi.org/10.14202/vetworld.2021.137-143 How to cite this article: Hidayatik N, Purnomo A, Fikri F, Purnama MTE (2021) Amelioration on oxidative stress, testosterone, and cortisol levels after administration of Vitamins C and $E$ in albino rats with chronic variable stress, Veterinary World, 14(1): 137-143.

\begin{abstract}
Background and Aim: Stress can cause physiological and biological disorders in the body. On the other hand, antioxidants from vitamins and minerals are effective for stress treatment. Therefore, this study aimed to evaluate the effect of the administration of Vitamins $\mathrm{C}$ and $\mathrm{E}$ on serum superoxide dismutase (SOD), malondialdehyde (MDA), catalase (CAT), glutathione peroxidase (GPx), testosterone, and cortisol activity in albino rats with chronic variable stress (CVS).

Materials and Methods: Twenty albino rats were randomly assigned into four treatment groups: $\mathrm{C}$ was administered normal saline; T1 was administered Vitamins C and E; T2 was only induced CVS; and T3 was induced CVS followed by Vitamins C and E administration. All treatments were applied for 4 weeks, respectively. Furthermore, $5 \mathrm{~mL}$ of blood samples were collected intracardially. Body weight data were collected for the initial and final weights. From serum samples, SOD, GPx, and CAT were measured using the enzymol method; MDA was measured using the high-performance liquid chromatography method; and testosterone and cortisol were measured using the enzyme-linked immunosorbent assay method. All variables were analyzed statistically using analysis of variance followed by the Duncan test $(p<0.05)$.
\end{abstract}

Results: Our findings showed that the T1 and T3 groups significantly decreased $(\mathrm{p}<0.001)$ compared to T2 in the following parameters: SOD, MDA, GPx, and cortisol. Meanwhile, CAT and testosterone levels in the T1 and T3 groups were significantly increased $(\mathrm{p}<0.001)$ compared to the T2 group. In addition, the weight gain in T1 and T3 groups was significantly increased $(\mathrm{p}<0.001)$ compared to T2 group.

Conclusion: It can be concluded that the administration of Vitamins C and E had a significant effect to alleviate SOD, MDA, GPx, and cortisol and to improve the testosterone level in albino rats with CVS.

Keywords: chronic variable stress, oxidative stress parameters, Vitamin C, Vitamin E.

\section{Introduction}

Stress can be categorized as acute or chronic, depending on the duration of the exposure. Both acute and chronic stresses are known as a major cause of physiological and biological disorders, especially due to their significant impact on the production of free radical or reactive oxygen species (ROS) [1-3]. The production of free radicals is influenced by external factors such as heat, trauma, noise, infection, radiation, hyperoxia, toxins, and physical exercise [4]. It is well known that normal cells produce small amounts of ROS as essential substances in the body, but their accumulation can damage macromolecules such as fats, proteins, carbohydrates,

Copyright: Hidayatik, et al. Open Access. This article is distributed under the terms of the Creative Commons Attribution 4.0 International License (http://creativecommons.org/licenses/ by/4.0/), which permits unrestricted use, distribution, and reproduction in any medium, provided you give appropriate credit to the original author(s) and the source, provide a link to the Creative Commons license, and indicate if changes were made. The Creative Commons Public Domain Dedication waiver (http:// creativecommons.org/publicdomain/zero/1.0/) applies to the data made available in this article, unless otherwise stated. and DNA structures [4-7]. In conditions of stress, it has been shown that there are increased antioxidant enzymes activities, including superoxide dismutase (SOD), catalase (CAT), and glutathione peroxidase (GPx) $[4,8]$. In addition, cortisol is known as one of the primary hormones that define stress conditions, as it has been reported that it increases during stress conditions [9-11] and will be affected by the decreased testosterone level. Testosterone is an active hormone that regulates libido and supports spermatid elongation during spermiogenesis $[12,13]$. As a result, stress has a negative impact on growth rate, feed consumption, body weight, libido, and animal production [14].

In the past decade, many studies were conducted using antioxidants from vitamins and minerals for stress treatment $[5,15]$. Vitamins $\mathrm{C}$ and $\mathrm{E}$ are known as non-enzymatic antioxidants that are effective for blocking the negative effects of oxidative stress [5]. Vitamin C can protect proteins, lipids, carbohydrates, and nucleic acids from damage by pro-oxidants generated during normal metabolism [16]. Vitamin $\mathrm{E}$ is the principal defense molecule against 
oxidant-induced membrane injury [5]. A combination of Vitamins $\mathrm{E}$ and $\mathrm{C}$ was reported to have decreased the effects of oxidative stress better than those of vitamins alone $[17,18]$.

The aim of this present study that utilized a modified chronic variable stress (CVS) from Mueller and Bale [19] was to evaluate the SOD, malondialdehyde (MDA), CAT, GPx, testosterone, and cortisol activities after the administration of Vitamins $\mathrm{C}$ and $\mathrm{E}$ in albino rats.

\section{Materials and Methods \\ Ethical approval}

This study was approved by Animal Ethics No. 443/HRECC.FODM/VII/2019 of Universitas Airlangga.

\section{Study period and location}

This study was conducted for 2 months (July and August 2019). Albino rats were reared in the Laboratory Animal Facility, Faculty of Veterinary Medicine, Universitas Airlangga. Laboratory examinations were performed at the Department of Veterinary Clinical Pathology and Physiology, Faculty of Veterinary Medicine, Universitas Airlangga and Gamma Scientific Biolab, Malang, East Java.

\section{Experimental design}

To assess the impact of CVS in this study, the body weight of the albino rats was monitored before and after the study. A total of 20 male albino rats were randomly divided into four treatment groups with five replications, respectively: $\mathrm{C}$ was administered normal saline; T1 was administered Vitamins $\mathrm{C}$ and $\mathrm{E}$; $\mathrm{T} 2$ was induced CVS; and T3 was induced CVS followed by Vitamins $\mathrm{C}$ and $\mathrm{E}$ administration.

The CVS was induced according to the Mueller and Bale method [19], but with a slight modification in terms of restraint, multiple cage, sleep deprivation, predator exposure, temperature stress, and noise (Table-1). Six painless, non-habituating stress models were performed, with the details as follows: Rats were restrained in a $900 \mathrm{~cm}^{2}$ enclosure area during the light cycle, multiple cage changes done during the light/dark cycle, and saturated beddings with water were placed overnight to cause sleep deprivation. Predator exposure was done by placing a cat in front of the enclosed cage with a wire mesh separation. Temperature stress was attained by setting it to $37^{\circ} \mathrm{C}$. Finally, crowded exposure was conducted using 100 decibels of sound during the light cycle.

Table-1: The chronic variable stress modification procedure.

\begin{tabular}{lc}
\hline Stress type and schedule & Total hours in 4 weeks \\
\hline Restraint, 20 min & $9 \mathrm{~h}$ \\
Multiple cage, 20 min for 2 h & $56 \mathrm{~h}$ \\
Sleep deprivation, 12 h & $336 \mathrm{~h}$ \\
Predator exposure, 24 h & $672 \mathrm{~h}$ \\
Temperature stress, $12 \mathrm{~h}$ & $336 \mathrm{~h}$ \\
Noise, 4 h & $112 \mathrm{~h}$ \\
\hline
\end{tabular}

After the respective stressor, rats were returned to their respective cages. Cages were cleaned and the litter was replaced before the rats were returned. The $\mathrm{T} 2$ and $\mathrm{T} 3$ groups were induced by CVS according to the aforementioned method. Furthermore, T1 and T3 groups were administered Vitamins $\mathrm{C}$ and $\mathrm{E}$. A combination dose of Vitamin C (Bio C, Indonesia) $7 \mathrm{mg} / \mathrm{kg}$ and Vitamin E (Nutrilite ${ }^{\mathrm{TM}}$, Indonesia) $5 \mathrm{mg} / \mathrm{kg}$ was used. Vitamins $\mathrm{C}$ and $\mathrm{E}$ were dissolved in drinking water $(0.1 \mathrm{~mL} / \mathrm{rats})$ and then administered orally after CVS induction. All treatments were applied for 4 weeks, respectively. After 4 weeks of treatment, all rats were sacrificed by cervical decapitation. Blood samples were collected intracardially for biochemical analysis.

\section{Serum evaluation}

A total of $5 \mathrm{ml}$ of the blood samples were collected intracardially. The blood sample was allowed to stand at room temperature for 15-30 min. Thereafter, it was centrifuged using centrifuge Hettich EBA $200^{\circledR}$ (Hettich, Germany) at $4000 \mathrm{rpm}$ for $15 \mathrm{~min}$. The resulting supernatant designated serum was carefully aspirated using a Pasteur pipette into a microtube and stored at $-4^{\circ} \mathrm{C}$. Serum testosterone and cortisol were estimated using the enzyme-linked immunosorbent assay method (My-Bio-Source ${ }^{\circledR}$, San Diego, CA, USA) [20]. The remaining serum was used to measure serum SOD, MDA, CAT, and GPx levels [21,22].

\section{Statistical analysis}

Data were expressed as mean \pm standard deviation and analyzed statistically using a one-way analysis of variance followed by the Duncan test for comparisons between the groups. Differences were considered significant at $p<0.05$. The analysis was performed using SPSS v25 (IBM, USA).

\section{Results}

\section{Body weight}

The increase in body weight of the albino rats during the study was significantly different between the groups. The highest increase in body weight was observed in the T1 group, while the lowest final body weight was recorded in the $\mathrm{T} 2$ group, being approximately $59 \%$ and $5 \%$, respectively. There was a significant increase in body weight in the T3 group $(p<0.001)$ compared to the T2 group. On the other hand, there was a more significant increase in the T1 group $(\mathrm{p}<0.05)$ compared to the T3 group (Table-2). This study demonstrated an increase in the percentage of body weight increase in the Vitamins $\mathrm{C}$ and $\mathrm{E}$ groups compared to the group exposed to CVS.

\section{Antioxidant enzyme levels}

The T1 and T3 groups showed significantly decreased $(p<0.001)$ levels of SOD, MDA, and GPx compared to the T2 group. Furthermore, the groups administered with Vitamins C and E (T1 and T3) had lower SOD levels, but the levels were not significantly 
different between these groups ( $p>0.05)$. Regarding MDA and GPx, their levels were significantly lower in the T1 and T3 groups $(\mathrm{p}<0.001)$ compared to the T2 group. However, the T1 group showed the lowest levels compared to the T3 group. On the other hand, the levels of CAT in the T1 and T3 groups were significantly higher $(\mathrm{p}<0.001)$ compared to the $\mathrm{T} 2$ group (Figure-1). The current study revealed the role of Vitamins $\mathrm{C}$ and $\mathrm{E}$ in reducing the levels of SOD, MDA, and GPx, which are parameters of oxidative stress.

Based on the regression analysis, the levels of SOD, MDA, and GPx had a negative correlation with increasing rat body weight (Figure-2). An increase in body weight was followed by a decrease in SOD, MDA, and GPx levels, with formulation; $\mathrm{y}=-2.6441 \mathrm{x}+553.83 ; \quad \mathrm{y}=-0.0199 \mathrm{x}+2.6009 ; \quad$ and $y=-0.0659 x+9.0877$, respectively. In contrast, CAT level had a positive correlation with increasing rat body weight (Figure-2). An increase in rat body weight was followed by an increase in CAT levels $(\mathrm{y}=0.2251 \mathrm{x}+13.058)$.

\section{Hormone levels}

Vitamins $\mathrm{C}$ and $\mathrm{E}$ administration also led to an increase in testosterone levels and a decrease in cortisol levels. When compared to T2, the testosterone levels in the T1 and T3 groups were shown to be significantly increased $(\mathrm{p}<0.001)$. However, T1 and T3 showed no significant difference $(\mathrm{p}>0.05)$ (Figure-3). In the cortisol determination, all groups showed a significant decrease in cortisol levels $(p<0.001)$ compared to the T2 group (Figure-3), thus proving that Vitamins $\mathrm{C}$ and $\mathrm{E}$ modulate stress reduction due to CVS.

The correlations of increased body weight with testosterone and cortisol levels were indicated to be positive and negative, respectively (Figure-2). Increased rat body weight was followed by an increase in testosterone levels $(\mathrm{y}=0.1417 \mathrm{x}-0.2107)$ and vice versa for cortisol levels $(y=-0.0149 x+1.6625)$.

Table-2: Body weight of the albino rats at the end of treatment.

\begin{tabular}{lccc}
\hline Groups & Initial weight $(\mathbf{g})$ & Final weight $(\mathbf{g})$ & \% increase in body weight \\
\hline C (control) & $153.0 \pm 1.58^{\mathrm{a}}$ & $222.4 \pm 5.03^{\mathrm{b}, * * *}$ & $45.4 \pm 4.28^{\mathrm{b}, * * *}$ \\
T1 (CE) & $151.6 \pm 1.34^{\mathrm{a}}$ & $240.2 \pm 7.69^{\mathrm{a}, * * *}$ & $58.5 \pm 5.53^{\mathrm{a},{ }^{* * * *}}$ \\
T2 (CVS) & $151.2 \pm 0.84^{\mathrm{a}}$ & $158.4 \pm 6.35^{\mathrm{c}}$ & $4.8 \pm 3.77^{\mathrm{c}}$ \\
T3 (CE+CVS) & $151.0 \pm 1.00^{\mathrm{a}}$ & $225.6 \pm 11.72^{\mathrm{b}, * * *}$ & $49.4 \pm 7.34^{\mathrm{b}, * * *}$ \\
\hline
\end{tabular}

Values are expressed in mean $\pm S D\left(n=5\right.$ animals for each four groups). Values are represented statistically ${ }^{a, b, c} w h e n$ compared with $\mathrm{C}$ group value; $* \mathrm{p}<0.05, * * \mathrm{p}<0.01, * * * \mathrm{p}<0.001$, when compared with T2 group value. CVS $=$ Chronic variable stress, $\mathrm{SD}=$ Standard deviation

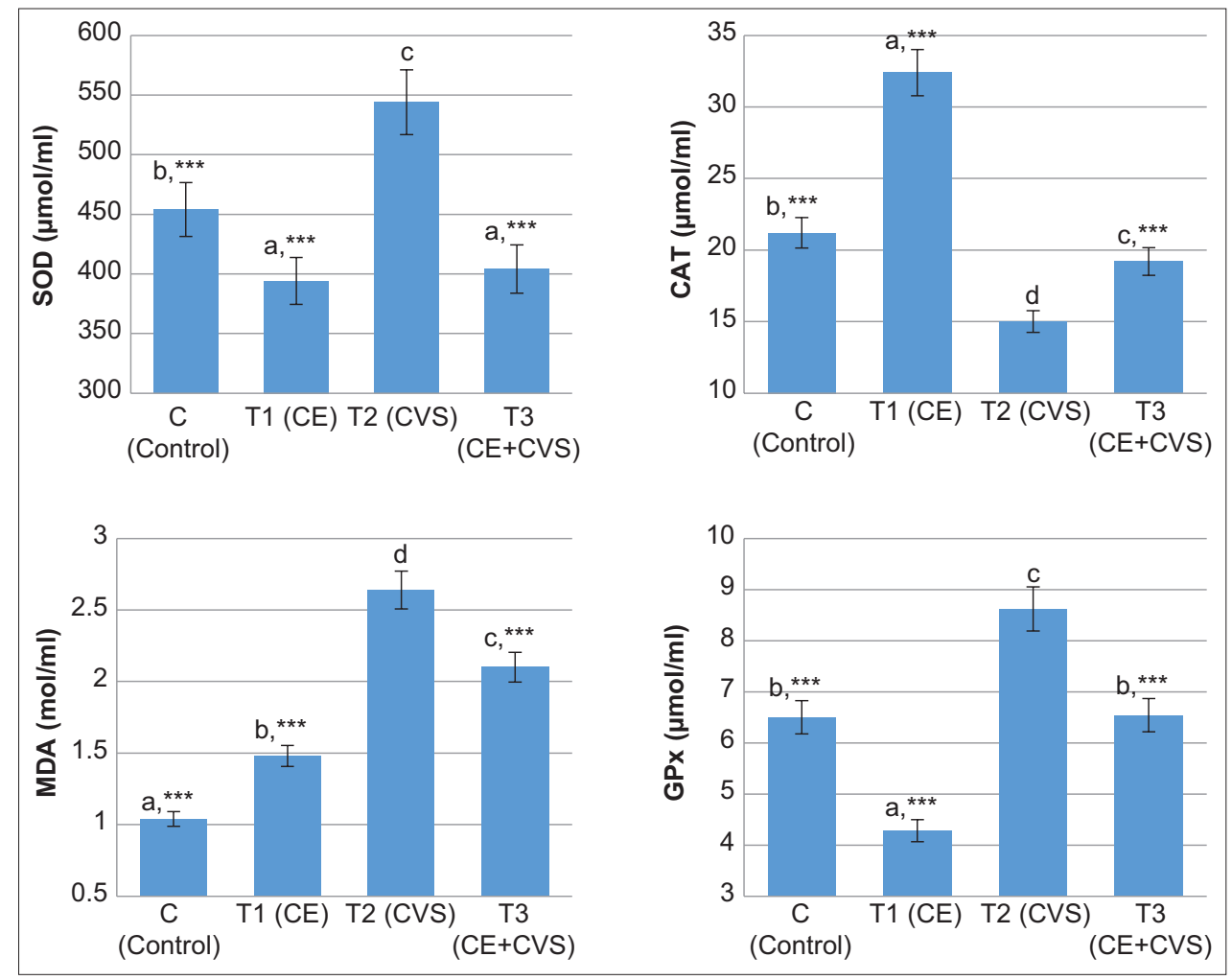

Figure-1: The activities of SOD, CAT, MDA, and GPx in serum after administration of Vitamins $C$ and $E$ in albino rats with chronic variable stress. Values are expressed in mean \pm standard deviation ( $n=5$ animals for each four groups). Values are represented statistically ${ }^{a, b, c, d}$ when compared with $C$ group value; $* p<0.05, * * p<0.01, * * * p<0.001$, when compared with $\mathrm{T} 2$ group value. $\mathrm{SOD}=$ Superoxide dismutase, $\mathrm{CAT}=$ Catalase, MDA=Malondialdehyde, GPx=Glutathione peroxidase. 


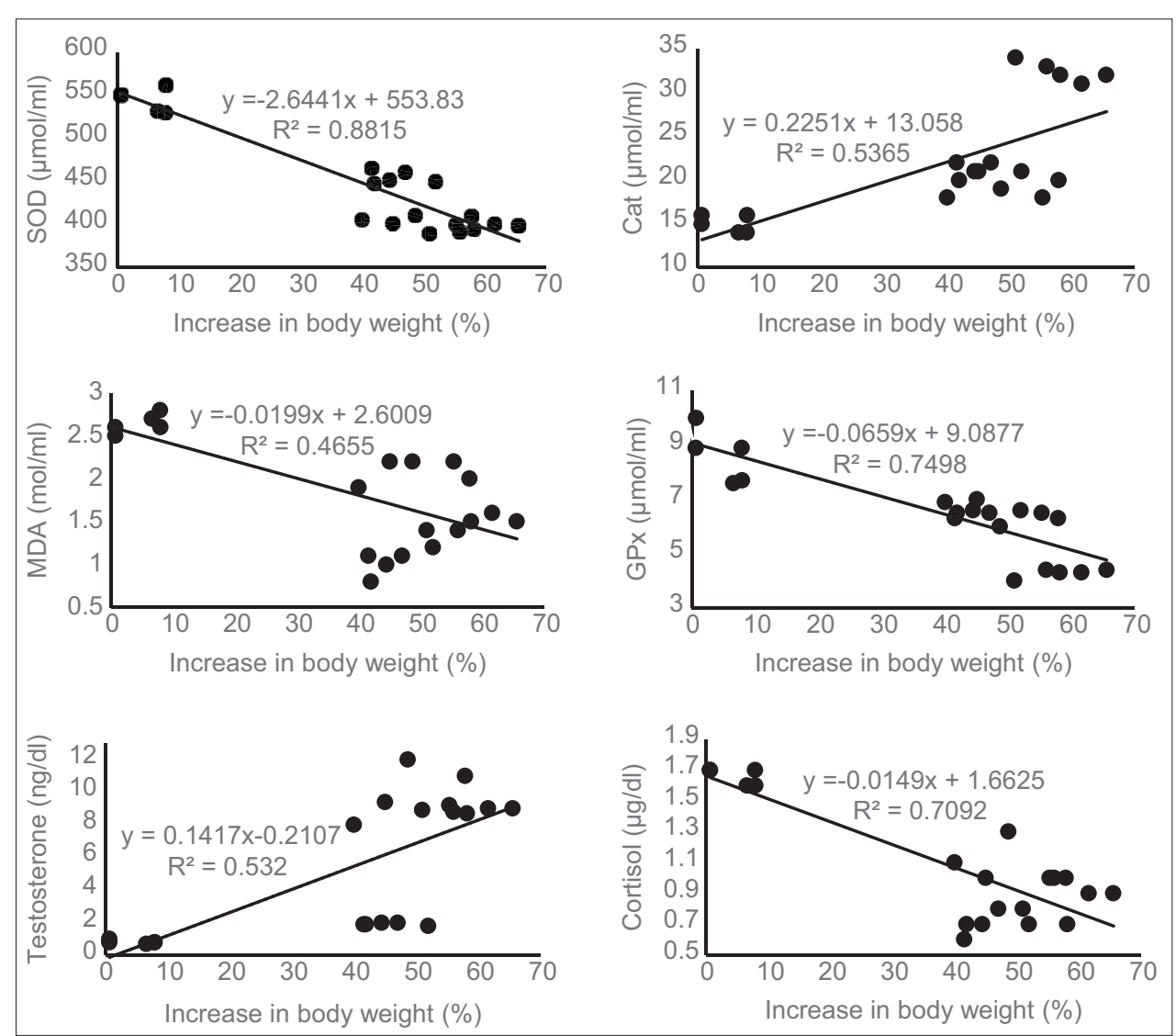

Figure-2: Regression plot for each parameter at increasing body weight.
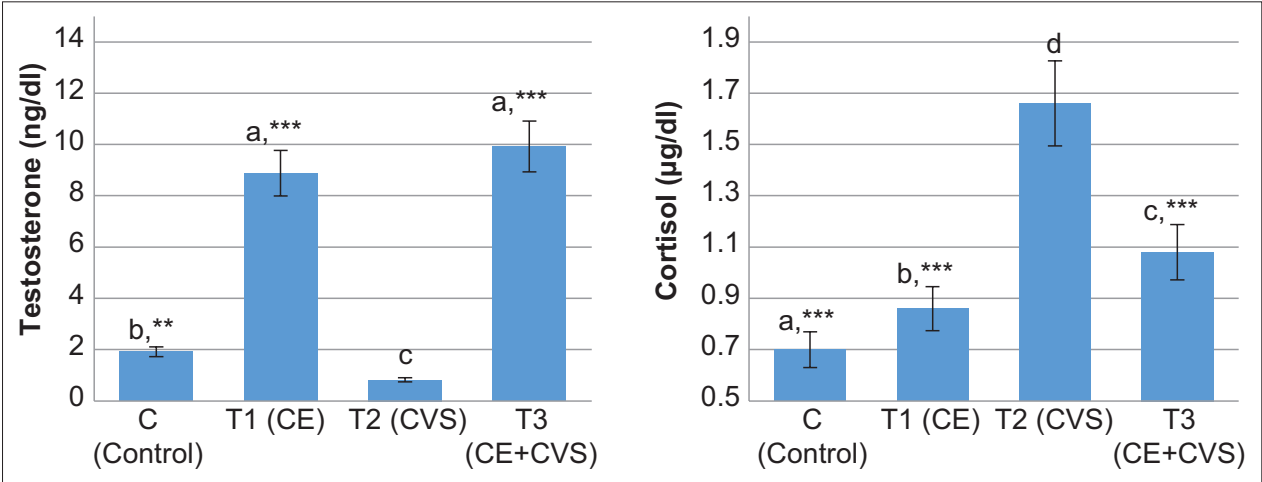

Figure-3: The level of testosterone and cortisol in serum after administration of Vitamins $\mathrm{C}$ and $\mathrm{E}$ in albino rats with chronic variable stress. Values are expressed in mean \pm standard deviation ( $n=5$ animals for each four groups). Values are represented statistically $a, b, c, d$ when compared with $C$ group value; $* p<0.05, * * p<0.01, * * * p<0.001$, when compared with T2 group value.

\section{Discussion}

In this study, we investigated the effect of combined treatment with Vitamins $\mathrm{C}$ and $\mathrm{E}$ on antioxidant enzymes activities and the levels of affected hormones in albino rats with CVS. Using these data, we obtained comparative information to elucidate the antioxidant effect of Vitamins $\mathrm{C}$ and $\mathrm{E}$ in CVS.

Vitamin $\mathrm{C}$ or $\mathrm{E}$ treatment alone was reported to be effective in reducing the negative effects of stress [22-24]. Vitamin C functions to maintain the fat-soluble Vitamin E. In particular, Vitamin $\mathrm{C}$ also plays a role in activating Vitamin $\mathrm{E}$ when it loses its antioxidant capacity by turning into tocopherol.
Vitamin $\mathrm{C}$ increases the antioxidant activity of Vitamin $\mathrm{E}$ by reducing chopheroxyl radicals into the active form of provitamin $\mathrm{E}$ [25]. A combination treatment of Vitamins $\mathrm{C}$ and $\mathrm{E}$ had been reported by several studies to reduce the oxidative stress in various conditions, that is, rats with diabetic pregnancy, heat stress in hen, and hypertensive rats [26,27].

Stress is a condition that can cause physiological disorders in the body through the response of ROS production. Stress can lead to weight loss, which occurs as a result of alterations in energy homeostasis regulation and reduced food intake [28-33]. Rats with CVS treated Vitamins $\mathrm{C}$ and $\mathrm{E}$ showed a significant increase in body weight. It was reported that Vitamin 
E supplementation could protect against changes in body weight and food intake due to stress [34].

In this present study, CVS resulted in increased SOD, MDA, GPx, and cortisol levels, while the CAT and testosterone levels were decreased. The fact that Vitamins $\mathrm{C}$ and $\mathrm{E}$ treatment in CVS rats resulted in the contrast suggests that the combination of Vitamins $\mathrm{C}$ and $\mathrm{E}$ administered improved antioxidant enzymes ability, endocrine function, and reduce lipid peroxidation in oxidative stress. This result was similar to those of several previous studies $[35,36]$. Increased antioxidant enzyme activities may be considered as a protective mechanism against stress-induced free radical production and lipid peroxidation [37].

SOD is an important parameter for measuring oxidative stress levels [38]. SOD is an enzyme that acts as a cellular antioxidant by catalyzing the free radical anion superoxide $\left(\mathrm{O}_{2}^{-}\right)$to produce hydrogen peroxide $\left(\mathrm{H}_{2} \mathrm{O}_{2}\right)$ and water $\left(\mathrm{H}_{2} \mathrm{O}\right)$, which is, in turn, degraded by CAT or GPx [39]. Electron transport disorders can be caused by stress through increased free radicals. Free radicals are unpaired molecules that are very reactive. Free radicals can change proteins, nucleic acids, and fatty acids in cell membranes and plasma lipoproteins [40]. Polyunsaturated fatty acid in cell membranes is easily reduced by free radicals through lipid peroxidation to produce MDA [37]. Lipid peroxidation can be improved by administering antioxidants. Lipid peroxidation is generally divided into three stages, that is, initiation, propagation, and termination. In the termination stage, antioxidants transfer hydrogen atoms, thereby reducing the reactive potential of the non-radical compounds [41]. The combination of Vitamins $\mathrm{E}$ and $\mathrm{C}$ reported reduces lipid peroxidation in vitro and in vivo [42]. The results of the present study are in accordance with the previous studies, which report that the combination of Vitamins $\mathrm{C}$ and $\mathrm{E}$ can reduce MDA levels in blood plasma $[18,43]$.

In addition, CAT is one of the most important antioxidant enzymes that use hydrogen peroxide as its substrate and maintains cellular redox homeostasis [39]. Although the levels CAT in this study was decreased in CVS rats treated with Vitamins C and E, this is similar to the study in rats with restraint stress. Furthermore, the combination treatment of Vitamins $\mathrm{C}$ and $\mathrm{E}$ in rats resulted in an increase in CAT activities [44]. This increase might be due to the expression of CAT, which is induced by many kinds of stresses, including peroxide stress [45].

Stress leads to an imbalance in physiological responses associated with the activation of the hypothalamo-pituitary-adrenocortical (HPA) axis. Activation of the HPA axis results in an elevation in circulating glucocorticoids (cortisol and corticosterone). In particular, glucocorticoids are the main markers of stress $[46,47]$. Increased cortisol level during stress was reported in wilds, farms, domestic, and laboratory animals, such as primates, giraffe, chicken, fish, dog, and rat [48-53]. In the present study, the cortisol level was decreased when CVS rats were treated with Vitamins $\mathrm{C}$ and $\mathrm{E}$. This finding was similar to a study involving stressed fish, in which increased cortisol levels did not result in depletion after administering Vitamins $\mathrm{C}$ and/or $\mathrm{E}$ as a supplement [52].

In contrast to the cortisol level, testosterone level was decreased during the stress condition. Stress affects the reproductive function through the activation of the HPA axis. HPA activation reduces the efficiency of the hypothalamus-pituitary-gonad axis [54,55]. Administering Vitamins $\mathrm{C}$ and $\mathrm{E}$ showed increased testosterone level in CVS rats, as well as in rats with testicular damage [56]. In addition, Vitamins $\mathrm{C}$ and $\mathrm{E}$ supplementation to diabetic rats resulted in the greatest improvement of the seminal parameters, such as sperm count, percentage sperm cell motility, percentage activity of motile cells, and percentage of cells with normal morphology [35].

\section{Conclusion}

This present study showed that Vitamins C and $\mathrm{E}$ were effective in increasing the SOD, MDA, GPx, and cortisol levels in albino rats with CVS. In addition, there were increasing levels of testosterone. This study also provided evidence that Vitamins $\mathrm{C}$ and $\mathrm{E}$ modulate the percentage increase in body weight. The increase in body weight was followed by an increase in the levels of SOD, MDA, GPx, and cortisol. Furthermore, the increase in body weight was also followed by an increase in testosterone levels.

\section{Authors' Contributions}

MTEP supervised the study. NH and AP conducted the study. MTEP helped in the statistical analysis of the data. NH and FF helped in the preparation of tables, revised, and submitted the manuscript. All authors read and approved the final manuscript.

\section{Acknowledgments}

The authors acknowledge the Directorate General Higher Education, Ministry of Research, Technology and Higher Education, Republic of Indonesia and Faculty of Veterinary Medicine, Universitas Airlangga, Indonesia, for providing fund support to carry out this study based on grant number 1408/UN3/2019.

\section{Competing Interests}

The authors declare that they have no competing interests.

\section{Publisher's Note}

Veterinary World remains neutral with regard to jurisdictional claims in published institutional affiliation.

\section{References}

1. Yaribeigi, H., Panahi, Y., Saharaei, H., Jonston, T.P. and Sahebkar, A. (2017) The impact of stress on body function: A review. Exp. Clin. Sci. J., 16: 1057-1072. 
2. Mina, C.B., Milota, D.P., Željko, B. and Kristina, B. (2019) The influence of chronic stress on health and coping mechanisms. Anamed, 14(1): 97-101.

3. Zeeshan, H.M.A., Lee, G.H., Kim, H.R. and Chae, H.J. (2016) Endoplasmic reticulum stress and associated ROS. Int. J. Mol. Sci., 17(3): 327.

4. Slimen, I.B., Najar, T., Ghram, A. and Abdrrabba, M. (2016) Heat stress effects on livestock: Molecular, cellular and metabolic aspects, a review. J. Anim. Physiol. Anim. Nutr., 100(3): 401-412.

5. Matic, I. (2018) The major contribution of the DNA damage-triggered reactive oxygen species production to cell death: Implications for antimicrobial and cancer therapy. Curr. Genet., 64(3): 567-569.

6. Herbet, M., Korga, A., Gawrońska, G.M., Izdebska, M., Piątkowska, C.I., Poleszak, E., Wróbel, A., Matysiak, W., Jodłowska, J.B. and Dudka, J. (2017) Chronic variable stress is responsible for lipid and DNA oxidative disorders and activation of oxidative stress response genes in the brain of rats. Oxid. Med. Cell. Longev., 2017: 1-10.

7. Borrow, A.P., Bales, N.J., Stover, S.A. and Handa, R.J. (2018) Chronic variable stress induces sex-specific alterations in social behavior and neuropeptide expression in the mouse. Endocrinology, 159(7): 2803-2814.

8. Ercan, N. and Koçkaya, M. (2017) Determination of malondialdehyde (MDA), superoxide dismutase (SOD) and glutathione peroxidase (GPx) levels in Kangal dogs with maternal cannibalism. Turk. J. Agric., 5(12): 1493-1496.

9. Haase, C.G., Long, A.K. and Gillooly, J.F. (2016) Energetics of stress: Linking plasma cortisol levels to metabolic rate in mammals. Biol. Lett., 12(1): 20150867.

10. Dinse, H.R., Kattenstroth, J.C., Lenz, M., Tegenthoff, M. and Wolf, O.T. (2017) The stress hormone cortisol blocks perceptual learning in humans. Psychoneuroendocrinology, 77(12): 63-67.

11. O'Connor, K.A., Brindle, E., Shofer, J., Trumble, B.C., Aranda, J.D., Rice, K. and Tatar, M. (2012) Indicators in the Baboon. Am. J. Phys. Anthropol., 145(4): 629-638.

12. Dutta, D., Park, I., Guililat, H., Sang, S., Talapatra, A., Singhal, B. and Mills, N.C. (2017) Testosterone regulates granzyme K expression in rat testes. Endocr. Regul., 51(4): 193-204.

13. Travison, T.G., Morley, J.E., Araujo, A.B., O’Donnell, A.B. and McKinlay, J.B. (2006) The relationship between libido and testosterone levels in aging men. J. Clin. Endocrinol. Metab., 91(7): 2509-2513.

14. Lara, L.J. and Rostagno, M.H. (2013) Impact of heat stress on poultry production. Animals., 3(2): 356-369.

15. Özkaya, M.O. and Nazrolu, M. (2010) Multivitamin and mineral supplementation modulates oxidative stress and antioxidant vitamin levels in serum and follicular fluid of women undergoing in vitro fertilization. Fertil. Steril., 94(6): 2465-2466.

16. Ryan, M.J., Dudash, H.J., Docherty, M., Geronilla, K.B., Baker, B.A., Haff, G.G., Cutlip, R.G. and Alway, S.E. (2010) Vitamin E and C supplementation reduces oxidative stress, improves antioxidant enzymes and positive muscle work in chronically loaded muscles of aged rats. Exp. Gerontol., 45(11): 882-895.

17. Afolabi, A.O., Olotu, O.O. and Alagbonsi, I.A. (2012) Vitamins $\mathrm{E}$ and $\mathrm{C}$ alleviate the germ cell loss and oxidative stress in cryptorchidism when administered separately but not when combined in rats. ISRN Pharmacol., 2012 (10): $1-8$.

18. Jena, B.P., Panda, N., Patra, R.C., Mishra, P.K., Behura, N.C. and Panigrahi, B. (2013) Supplementation of Vitamin $\mathrm{E}$ and $\mathrm{C}$ reduces oxidative stress in broiler breeder hens during summer. Food Nutr. Sci., 4(8): 33-37.

19. Mueller, B.R. and Bale, T.L. (2006) Impact of prenatal stress on long term body weight is dependent on timing and maternal sensitivity. Physiol. Behav., 88(4-5): 605-614.

20. Purnama, M.T.E., Dewi, W.K., Prayoga, S.F., Triana, N.M.,
Aji, B.S.P.A., Fikri, F. and Hamid, I.S. (2019) Preslaughter stress in banyuwangi cattle during transport. Indian Vet. J., 96(12): 50-52.

21. Karatas, F., Karatepe, M. and Baysar, A. (2002) Determination of free malondialdehyde in human serum by high-performance liquid chromatography. Anal. Biochem., 311(1): 76-79.

22. Omidi, A., Namazi, F., Jabire, S., Afsar, M., Honarmand, M. and Nazifi, S. (2016) The effects of starvation and refeeding on oxidative stress parameters (MDA, SOD, GPx), lipid profile, thyroid hormones and thyroid histopathology in male Wistar rats. Int. Arch. Med., 9(238): 1-10.

23. Fumeron, C., Nguyen-khoa, T., Saltiel, C., Kebede, M., Buisson, C., Dru, T.B., Lacour, B. and Massy, Z.A. (2005) Effects of oral Vitamin C supplementation on oxidative stress and inflammation status in haemodialysis patients. Nephrol. Dial. Transplant., 20(9): 1874-1879.

24. Panda, A.K. and Cherian, G. (2014) Role of Vitamin E in counteracting oxidative stress in poultry. J. Poult. Sci., 51(2): 109-117.

25. Popovic, L.M., Mitic, N.R., Miric, D., Bisevac, B., Miric, M. and Popovic, B. (2015) Influence of Vitamin C supplementation on oxidative stress and neutrophil inflammatory response in acute and regular exercise. Oxid. Med. Cell. Longev., 2015(1): 1-7.

26. Tantavisut, S., Tanavalee, A., Honsawek, S., Suantawee, T. and Ngarmukos, S. (2017) Effect of Vitamin E on oxidative stress level in blood, synovial fluid, and synovial tissue in severe knee osteoarthritis: A randomized controlled study. BMC Musculoskelet. Disord., 18(1): 1-9.

27. Ognjanović, B.I., Marković, S.D., Dordević, N.Z., Trbojević, I.S., Štajn, A.Š. and Saičić, Z.S. (2010) Cadmium-induced lipid peroxidation and changes in antioxidant defense system in the rat testes: Protective role of coenzyme Q10 and Vitamin E. Reprod. Toxicol., 29(2): 191-197.

28. Cederberg, J., Simán, C.M. and Eriksson, U.L.F. (2001) Combined treatment with Vitamin E and Vitamin C decreases oxidative stress and improves fetal outcome in experimental diabetic pregnancy. Pediatr. Res., 49(6): 755-762.

29. Chen, X., Touyz, R.M., Park, J.B. and Schiffrin, E.L. (2001) Antioxidant effects of Vitamins $\mathrm{C}$ and $\mathrm{E}$ are associated with altered activation of vascular NADPH oxidase and superoxide dismutase in stroke-prone SHR. Hypertens, 38(2): 606-611.

30. Harris, R.B.S., Mitchell, T.D., Simpson, J., Redmann, S.M., Youngblood, B.D. and Ryan, D.H. (2002) Weight loss in rats exposed to repeated acute restraint stress is independent of energy or leptin status. Am. J. Physiol. Regulat. Integr. Comp. Physiol., 282(1): 77-88.

31. Raynaud, A., Meunier, N., Acquistapace, A. and Bombail, V. (2015) Chronic variable stress exposure in male Wistar rats affects the first step of olfactory detection. Behav. Brain Res., 291: 36-45.

32. Jeong, J.Y., Lee, D.H. and Kang, S.S. (2013) Effects of chronic restraint stress on body weight, food intake, and hypothalamic gene expressions in mice. Endocrinol. Metab., 28(4): 288-296.

33. Ottenweller, J.E., Servatius, R.J., Tapp, W.N., Drastal, S.D., Bergen, M.T. and Natelson, B.H. (1992) A chronic stress state in rats: Effects of repeated stress on basal corticosterone and behavior. Physiol. Behav., 51(4): 689-698.

34. Fahami, N.A.M., Ismail, N.M. and Khalid, K.B.A. (2005) Effect of Vitamin $\mathrm{E}$ on food intake and body weight in rats exposed to restraint stress. Toxicology, 15(2): 81-86.

35. Bassey, I.E., Ikpi, D.E., Kokoabasi, I., Isong, P., Okon, U., Onyeukwu, C.C., Nwankwo, N.P., Eze, I., Ewa, D., Kokoabasi, I., Isong, P. and Okon, U. (2020) Effect of combined calcium, magnesium, Vitamin $\mathrm{C}$ and $\mathrm{E}$ supplementation on seminal parameters and serum oxidative stress markers in fructose-induced diabetic Wistar rats on seminal parameters and serum oxidative stress markers in 
fructose-induced. Arch. Physiol. Biochem., 2020(1): 1-8.

36. Hosseinabadi, M.B., Khanjani, N., Norouzi, P., Mirzaii, M. and Biganeh, J. (2020) Investigating the effects of Vitamins E and $C$ on oxidative stress and hematological parameters among power plant workers : A double-blind randomized controlled clinical trial. Toxicol. Ind. Health, 36(2): 99-109.

37. Min, Y.N., Niu, Z.Y., Sun, T.T., Wang, Z.P., Jiao, P.X., Zi, B.B., Chen, P.P., Tian, D.L. and Liu, F.Z. (2018) Vitamin E and Vitamin C supplementation improves antioxidant status and immune function in oxidative-stressed breeder roosters by up-regulating expression of GSH-Px gene. Poult. Sci., 97(4): 1238-1244.

38. Altan, Ö., Pabuçcuoğlu, A., Altan, A., Konyalioğlu, S. and Bayraktar, H. (2003) Effect of heat stress on oxidative stress, lipid peroxidation and some stress parameters in broilers. Br. Poult. Sci., 44(4): 545-550.

39. Buettner, G.R. (2011) Superoxide dismutase in redox biology: The roles of superoxide and hydrogen peroxide. Anticancer Agents Med. Chem., 11(4): 341-346.

40. Nandi, A., Yan, L., Jana, C.K. and Das, N. (2019) Review article role of catalase in oxidative stress-and age-associated degenerative diseases. Oxid. Med. Cell. Longev., 2019(1): $1-19$.

41. Akbarian, A., Michiels, J., Degroote, J., Majdeddin, M. and Golian, A. (2016) Association between heat stress and oxidative stress in poultry; mitochondrial dysfunction and dietary interventions with phytochemicals. J. Anim. Sci. Biotechnol., 7(1): 37.

42. Yang, H., Cui, X., Dai, X., Deng, Y. and Shi, F. (2015) Carbon-catalysed reductive hydrogen atom transfer reactions. Nat. Commun., 6(1): 1-11.

43. Porkkala-sarataho, E., Salonen, J.T., Nyysso, K., Kaikkonen, J., Salonen, R., Ristonmaa, U., Diczfalusy, U., Brigelius-flohe, R., Loft, S. and Poulsen, H.E. (2000) Long-term effects of Vitamin E, Vitamin C, and combined supplementation on urinary 7-hydro-8-oxo-2'-deoxyguanosine, serum cholesterol oxidation resistance of lipids in nondepleted men. Arterioscler. Thromb. Vasc. Biol., 20(9): 2087-2093.

44. Harsini, S.G., Habibiyan, M., Moeini, M.M. and Abdolmohammadi, A.R. (2012) Effects of dietary selenium, Vitamin E, and their combination on growth, serum metabolites, and antioxidant defense system in skeletal muscle of broilers under heat stress. Biol. Trace Elem. Res., 148(3): 322-330.
45. Zaidi, S.M.K. and Banu, N. (2004) Antioxidant potential of Vitamins $\mathrm{A}, \mathrm{E}$ and $\mathrm{C}$ in modulating oxidative stress in rat brain. Clin. Chim. Acta, 340(1-2): 229-233.

46. Jamieson, D.J. (1998) Oxidative stress responses of the yeast saccharomyces cerevisiae. Yeast, 14(16): 1511-1527.

47. Chmelíkováa, E., Bolechová, P., Chaloupková, H., Svobodová, I., Jovicic, M. and Sedmíková, M. (2019) Salivary cortisol as a marker of acute stress in dogs: A review. Dom. Anim. Endocrinol., 72: 1-10.

48. Packard, A.E., Ghosal, S., Herman, J.P., Woods, S.C. and Ulrich-Lai, Y.M. (2014) Chronic variable stress improves glucose tolerance in rats with sucrose-induced prediabetes. Psychoneuroendocrinology, 47(5): 178-188.

49. Bashaw, M.J., Sicks, F., Palme, R., Schwarzenberger, F., Tordiffe, A.S.W. and Ganswindt, A. (2016) Non-invasive assessment of adrenocortical activity as a measure of stress in giraffe (Giraffa camelopardalis). BMC Vet. Res., 12(1): 235.

50. Carnegie, S.D., Fedigan, L.M. and Ziegler, T.E. (2011) Social and environmental factors affecting fecal glucocorticoids in wild, female white-faced capuchins (Cebus capucinus). Am. J. Primatol., 73(9): 861-869.

51. Fraňková, M., Palme, R. and Frynta, D. (2012) Family affairs and experimental male replacement affect fecal glucocorticoid metabolites levels in the Egyptian spiny mouse Acomys cahirinus. Zool. Stud., 51(3): 277-287.

52. Heistermann, M., Palme, R. and Ganswindt, A. (2006) Comparison of different enzymeimmunoassays for assessment of adrenocortical activity in primates based on fecal analysis. Am. J. Primatol., 68(3): 257-273.

53. Ortuno, J., Esteban, M.A. and Meseguer, J. (2003) The effect of dietary intake of Vitamins $\mathrm{C}$ and $\mathrm{E}$ on the stress response of gilthead seabream (Sparus aurata L.). Fish Shellfish Immunol., 14(2): 145-156.

54. Ostner, J., Kappeler, P. and Heistermann, M. (2008) Androgen and glucocorticoid levels reflect seasonally occurring social challenges in male red fronted lemurs (Eulemur fulvus rufus). Behav. Ecol. Sociobiol., 62(4): 627-638.

55. Dobson, H. and Smith, R.F. (1995) Stress and reproduction in farm animals. J. Reprod. Fertil. Suppl., 49(1): 451-461.

56. Zare, S., Hossein Dabbaghmanesh, M., Noorafshan, A., Koohpeyma, F., Bakhshayeshkaram, M. and MontazeriNajafabady, N. (2019) Protective effect of Vitamin E and Vitamin $\mathrm{C}$ alone and in combination on testicular damage induced by sodium metabisulphite in rats: A stereological study. Andrology, 51(2): e13193. 